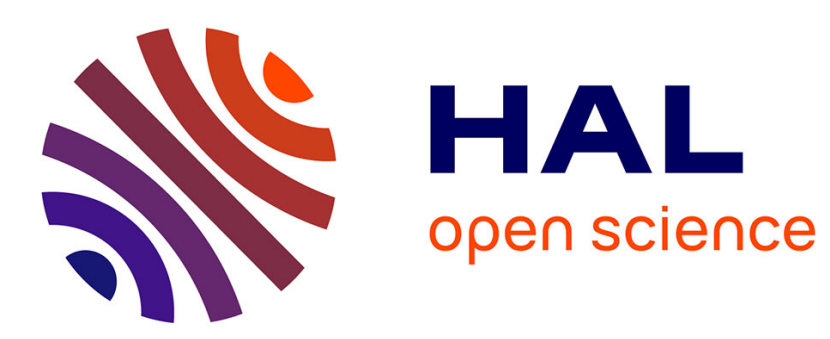

\title{
Framework for a Competency-Driven, Multi-Viewpoint, and Evolving Learner Model
}

\author{
Lucie Moulet, Olga Marino, Richard Hotte, Jean-Marc Labat
}

\section{To cite this version:}

Lucie Moulet, Olga Marino, Richard Hotte, Jean-Marc Labat. Framework for a Competency-Driven, Multi-Viewpoint, and Evolving Learner Model. ITS 2008 - 9th International Conference on Intelligent Tutoring Systems, Jun 2008, Montreal, Canada. pp.702-705, 10.1007/978-3-540-69132-7_83 . hal00579354

\section{HAL Id: hal-00579354 \\ https://hal.science/hal-00579354}

Submitted on 23 Mar 2013

HAL is a multi-disciplinary open access archive for the deposit and dissemination of scientific research documents, whether they are published or not. The documents may come from teaching and research institutions in France or abroad, or from public or private research centers.
L'archive ouverte pluridisciplinaire HAL, est destinée au dépôt et à la diffusion de documents scientifiques de niveau recherche, publiés ou non, émanant des établissements d'enseignement et de recherche français ou étrangers, des laboratoires publics ou privés. 


\title{
Framework for a Competency-Driven, Multi- Viewpoint, and Evolving Learner Model
}

\author{
Lucie Moulet $^{1,2}$, Olga Marino ${ }^{1}$, Richard Hotte ${ }^{1}$, and Jean-Marc Labat ${ }^{3}$ \\ ${ }^{1}$ LICEF Research Center, Télé-université / Université du Québec À Montréal \\ 100, rue Sherbrooke Ouest, Montréal, QC, H2X 3P2, Canada \\ \{lucie.moulet, olga.marino, richard.hotte\}@licef.ca \\ ${ }^{2}$ CRIP5, Université Paris Descartes - Paris 5 \\ 45, rue des Saints Pères, 75270 Paris Cedex 06, France \\ ${ }^{3}$ LIP6, Université Pierre et Marie Curie - Paris 6 \\ 104 avenue du Président Kennedy, 75016 Paris, France \\ jean-marc.labat@upmc.fr
}

\begin{abstract}
Considering learning as a dynamic, evolving, social, and lifelong process which occurs in a wide variety of contexts, we aim to improve online learning by offering learning adaptation possibilities, lifelong learning followup, learning evolution follow-up, openness to the learner's contexts (personal, professional, and academic), and openness to actors involved in the learning process. To achieve this goal, we propose the development of a meta-model for learner models based on competencies, integrating learner production and personal and professional information, IPP, evolving in time and taking into account different viewpoints. This meta-model may be used for creating different kind of learner models which serve different purposes: adaptation of learning to the learner's cognitive state, learning evaluation, self-reflection, team work... From these kinds of models, models representing individuals will be instantiated.
\end{abstract}

Keywords: Online learning, learner model, personalization, competency. 


\section{Introduction}

Online learning fills the need for lifelong learning and is supported by the development of information technologies. The issues around this theme are multiple. We are especially interested in work done around actors (learner, peers, professor...) and their knowledge and competencies. In this project, we will consider learning as a dynamic, evolving, social, and lifelong process that occurs in a variety of contexts.

Our research issue is how to create a learner model that offers learning adaptation possibilities, lifelong learning and learning evolution follow-up, openness to the learner's contexts (personal, professional, and academic), and openness to the actors involved in the learning process. The learner model needs to be semantically rich, should evolve in time for learning never stops, must take into account the social dimension of learning, and should be formal, and interoperable. In this paper, we will present the conceptual model of a meta-model for learner models. The meta-model allows the design of different kinds of learner model depending on the purposes of these ones (for evaluation, collaboration, self-reflection...). And from those kinds of learner models, we can instantiate learner models modeling individuals. We start by presenting our cognitive learner model. In the following sections, we describe its multi-viewpoint and evolving characteristics as well as the mechanism on which the model interactions are based. We end with the main conclusions and the future work.

\section{A cognitive learner model}

We propose a cognitive learner model based on competencies which integrates personal and professional information as well as learner's productions. The model is owned by the learner and connects, as needed and with the learner agreement, to different online learning systems. It is semantically rich (based on competencies), formal, and interoperable. And it may be used for different purposes: adapting learning, facilitating team work, evaluation of learning, self-reflection...

Competencies are the heart of our model. We will work with Paquette's definition [1] of a competency: a relation between actor, skill, knowledge and context. We choose this competency approach because it offers a strong semantic referencing to link the learner model with the learning resources. We assume that semantic referencing on competencies is stronger than semantic referencing on knowledge for they consider skills and context. We believe that this semantic referencing is essential for a pertinent personalization according to learner expectations and needs.

The second component of our model is the ePortfolio. It contains the learner's productions. Our learner model will have core competencies as well as domain competencies for each domain the learner is involved in.

The third component is the personal and professional information (PPI), the learner's link to his broad world. Learning is a continuous process which occurs in different contexts, including the personal and professional ones. PPI and learner's productions are linked to the competencies they illustrate. 


\section{Multi-viewpoint learner model}

We have already stated that learning takes place in the learner's different learning situations and through social interactions [2]. Different units of learning as well as actors interact with the learner and should be allowed to register the result of these interactions in the learner model. The learner model is thus seen from different viewpoints. A viewpoint is "A mental position from which things are viewed" [3].

Our learner model is a multi-viewpoint model composed of the core learner model and the related learner model viewpoints. The core learner model includes objective information such as PPI and productions, as well as the learner information that has the consensus of the different human and machine actors. Linked to this core learner model, there are as many viewpoints as there are differentiated observers allowed to modify the learner model (tutors, professors, peers, learning units, etc.) Those viewpoints are not pre-established but settled by the learning context of the learner (their can be a view point by individual or a viewpoint by roles (learner, professor...)). A viewpoint contains competencies along with links between those competencies and the learner's PPI and productions.

When a modification is proposed by one of the actors in the system, the viewpoint corresponding to this actor is updated with the modification and a modification proposal mechanism is launched. This mechanism is defined outside of the model and takes into account organizational hierarchies and conflict solving strategies. If agreement is obtained, the modification is reflected in the core model.

\section{Evolving learner model}

For us, learning is a knowledge building process proceeding from the interaction between a learner and his/her environment [4]. From this environment the learner pulls off his/her learning conditions. We can then consider learning as a social act which evolves taking into account interaction with the learner's environment, making it a dynamic learning process. A learner model has to reflect this dynamic characteristic and must be evolving too. An evolving learner model updates itself according to the learning progress. Thus, during learning, different versions of the model will be created. Those versions need to be managed.

To deal with this evolutionary dimension, the learner model proposed in the preceding section will be extended to include different learner model versions. For this, we will integrate a version control system into our learner model. The model can then be searched by viewpoint or by version, and the evolution of a competency can be tracked in time.

\section{Learner model interaction}

We state that the learner is the owner of his/her model. Thus, any manipulation of the model should have the agreement of the learner. As the model will be in interaction 
with actors and online learning systems, the learner should agree on those actors and systems interactions. For this, we propose to use contracts. Contracts are used in computer science to specify the relations between different actors (or components or systems or models...) [5]. For example, if a learner wishes to take a course at a specific university, this latter may require accessing all information contained in the learner model. This access allowance could be specified in a contract. More precisely in our project, contracts will allow the specification of which kinds of actors can interact with the model and which action each of these actor kinds can take. Contracts can also specify when modifications can take place (evolution characteristic of the model).

Interactions can be of two kinds. The first one consists of extending the model with new information. The second one consists of consulting the information contained in the model (to adapt learning for example).

\section{Conclusion and further work}

This research project aims to improve online learning by offering learning adaptation possibilities, lifelong learning follow-up, learning evolution follow-up, openness to the learner's contexts (personal, professional, and academic), and openness to actors involved in the learning process. To achieve this goal, we propose the development of a meta-model for the design of learner models based on competencies that integrate learner production and IPP, that evolve in time as well as learning progress, and that take into account different viewpoints while remaining interoperable. Those models may be of different kinds depending on their purposes: adapting learning to the learner's cognitive state, learning evaluation, self-reflection, teamwork... The strength of this model is its ability to integrate different elements in the same learner model: a learner cognitive model (knowledge and competencies), a learner production model, a multi-viewpoint model, and an evolving model.

The next step of this project is to complete a prototype development. This development has begun and is based on Java, using Castor Project to map Java objects and XML files, and integrating the Subversion version control system to manage the model's evolution in time.

\section{References}

1. Paquette, G., Rosca, I.: An Ontology-based Referencing of Actors, Operations and Resources in eLearning Systems. In: SW-EL/2004 Workshop. Einhoven (2004)

2. Lasnier, F.: Réussir la formation par compétences. Guérin, Montréal (2000)

3. WordNet, lexical database for the English language, http://wordnet.princeton.edu/

4. De Vries, E., Baillé, J.: Apprentissage: référents théoriques pour les EIAH. In M. GrandBastien and J.-M. Labat (eds.), Environnements informatiques pour l'apprentissage humain. pp. 27--46. Hermès/Lavoisier, Paris (2006)

5. Bachman, F., Bass, L., Buhman, C., Comella-Dorda, S., Long, F., Robert, J., Seacord R., Wallnau, K.: Volume II: Technical Concepts of Component-Based Software Engineering. Technical Report, Carnegie Mellon University, Pittsburgh, (2000) 